\title{
Mineral and Phytochemical Composition of Cleome Gynandra Methanolic Extract
}

\author{
Wanjala Wakhisi Charles*, Gicheru Muita Michael, Mwangi Eric \\ Kenyatta University, School of Pure and Applied Sciences, Nairobi, Kenya
}

* Corresponding Author email: chals2030@gmail.com

Article History

Received: 10 December 2019

Revised: 08 March 2020

Accepted: 10 April 2020

Published: 11 April 2020

Student(s)

- Charles Wanjala Wakhisi

Academic Year: 2019-20

Course Level: Master

Course Name: M.Sc. (Immunology)

Course year: $3^{\text {rd }}$ Year/ $2^{\text {nd }}$ Semester

Mentar(s)

- $\quad$ Michael Muita Gicheru

- $\quad$ Eric Mwangi

\section{ABSTRACT}

The study was done to evaluate the mineral and phytochemical composition of the methanolic extract of Cleome gynandra (spider plant). The plant is used as a traditional vegetable in some communities in sub-Saharan Africa and Asia. The plant has also been reported to have some medicinal effect due to presence of phytochemicals but its pharmacological and phytochemical profile has not been fully established. Collection and authentication of the plant was done followed by extraction using methanol as a solvent. The phytochemical investigation was done using both chemical analysis and chromatography method by use of a Gas chromatography mass spectroscopy (GCMS) system as per standard protocol. Cleome gynandra was found to contain some mineral compounds of nutritional importance and phytochemicals with potential medicinal importance. The phytochemicals analyzed include saponins, flavonoids, tannins, alkaloids, cardiac glycosides, terpanoids and polyphenols. These different phytochemicals can be further studied and their potential medicinal importance analyzed. The study concluded that Cleome gynandra contains phytochemicals with potentially important medicinal value. The plant (Cleome gynandra) can also be used as an important nutritional source of some essential nutrients like Vitamin $\mathrm{C}$ and beta carotene. It can also be a good source of some mineral elements like iron, selenium, cobalt, copper, zinc and manganese. This can be important for families in rural areas and for the low-income households in both rural and urban areas as a source of nutrients.

Keywords: Cleome gynandra, spider plant, phytochemicals, trace minerals

\section{Introduction}

The spider plant (Cleome gynandra) is a nutritious vegetable herb plant which grows in many regions of subSaharan Africa and Asia. It has been reported to have high levels of essential nutrients like L-ascorbic (vitamin C), tochopherols (Vitamin E) and pro-vitamin A ( $\beta$-carotene). It has also been reported to have medicinal properties [1]. The pharmacological properties of the spider plant are most probably due to the phytochemicals synthesized by the plant cells which are mainly secondary metabolites. The spider plant belongs to the Cleome Genus. Cleome is a genus of the family Cleomaceae (formerly Capparaceae) is a major 
group of angiosperms, comprising many species found in tropical and sub-tropical areas of the globe. Cleomaceae family, which are among the flowering plants are Brassicales (or Cruciales) order, and they have in excess of 764 species which belong to a total of 12 different genera of which Cleome is the largest genus having approximately 601 species of ecological, ethnobotanical, and of course medicinal importance [2]. The bitter taste of the plant leaves is due to phytochemicals produced by the plant and also gives the spider plant anti herbivory properties. Herbal plants can be used as a cheaper, less toxic and more readily available forms of medicines as compared to conventional medicines, but the utilization of some plants extracted products as medicines without determination of toxicity using modern methods can cause serious side effects or even mortality. The medicinal use of most herbal plants, including Cleome gynandra have been documented but have not been authenticated. Some medicinal plants might also have some therapeutic effect for more than one condition. Medicines derived from plants still play an important role in health care, and about $80 \%$ of the population in countries that are developing depend on traditional medicines for basic health care [3, 4]. Cleome gynandra has some medicinal properties. In the country of Uganda, the spider plant is utilized for labor induction in infant delivery [5]. After child delivery, the mothers are given Cleome gynandra to improve milk production and cause blood formation. Cleome gynandra is also used for migraine alleviation, pneumonia, vertigo, headache, vomiting, septic ears, stomach ailments and diphtheria. The plant is traditionally also utilized as an eyewash and it is given to boys after being circumcised $[2,6]$. The medicinal properties of the spider plant have not been fully investigated and also the dosage and toxicity of the plant have not been fully established. The main objective of this study was to determine the mineral and phytochemical profile of Cleome gynandra through both chemical analysis and chromatography using the Gas chromatography mass spectroscopy (GCMS) methods and also elucidate the phytochemicals identified and their possible medicinal properties and toxicity. The spider plant has been reported in literature to have a number pharmacological effect these include, anti-inflammatory effect and as a pain reliever, antioxidant, anticancer, immunomodulatory effect, antidiabetic and antifungal effect [2,7]. Traditionally a number of ethnic communities in Africa and Asia have reported the spider plant to treat some diseases like, the sap of leaves is used as a pain reliever especially cerebral pain, and Sap from pounded leaves is pressed into ears, nostrils, and eyes to treat fits caused by epilepsy and infections of the ear. A mixture of bubbled roots and leaves is regulated to encourage labor pain in pregnant ladies, treat stomach-throb and constipation, treat conjunctivitis, treat serious thread worm disease, relieve burning chest pains and the leaves are utilized to treat joint inflammation $[2,7,8]$.

Leaves have shown to be rubefacient and vesicant and used to treat neuralgia, otalgia, rheumatism, and stiffness. The leaves are rubbed on the affected parts. In Taiwan, it is utilized to treat looseness of the bowels, gonorrhea, fever, and rheumatoid arthritis. In India, the plant has been utilized as a rubefacient and antihelmintic agents. Leaves are applied directly above the injuries to prevent sepsis. The plant is also used to treat piles, different stomach aches and in tumors. The juice of the root is utilized to treat fevers, bruised leaves are applied to boils to stop pus discharge, infusion from leaves is utilized to treat iron deficiency, sap from the leaves used to cure intermittent intestinal sickness and leaves are rubbed onto the skin to relieve pneumonia. An infusion of the leaves utilized as an eyewash. Seeds are anthelmintic and rubefacient and are consumed for the removal of roundworms, or a mixture is applied externally on the stomach as a painkiller $[2,6,8]$. Seeds are blended with oil and applied to the scalp to treat headache, Mixture of seed controls coughing, Seeds are also utilized by veterinarians to treat stomach pains, leaves and the plant have anti-ticks and fleas preventive properties. A decoction of roots is accounted for to have gentle febrifugal properties and anthelmintic properties [6-15]. However, the efficacy of the spider plant and long-term safety is not well known. For its rational use it is important to study its efficacy and safety as well as determine its phytochemical, trace metal and heavy metal content. The information generated from this study will be important to health providers and users of these herbs as an alternative medicine and for further studies on its medicinal properties. 


\section{Materials and Methods}

\subsection{Collection and Drying of Plant Samples}

Six kilograms of the plant samples were collected. The identity of each of the plants was authenticated by a qualified taxonomist. The leaves were harvested and the fresh leaves are cut into small pieces and put under a shade at room temperature to dry for one week. The dried leaves were put in an electric mill and ground into powder then it was put away from light in a closed dry plastic of glass jar at $20^{\circ} \mathrm{C}$ for further study.

\subsection{Preparation of the Plant Methanolic Extracts}

The leaves Methanolic extract of the spider plant was extracted as follows. 50 grams of the plant leaves were air dried and ground into fine powder with an electrical blender. The blended material was then put in a beaker and $10 \mathrm{ml}$ of absolute methanol was added at favourable temperature $\left(28 \pm 2^{\circ} \mathrm{C}\right)$. The sample was then agitated to extract the phytochemicals by using a rotary shaker. Extraction lasted for 2 days. The mixture was allowed to decant and the solvent removed by a rota vapour at room temperature to leave the methanolic extract.

\subsection{Analysis of Trace Metals}

Total Reflection X-Ray Fluorescence (TXRF) system was used to determine the trace metal content of Chromium, Copper, Zinc, Manganese, Manganese, Iron, Nickel and Calcium in the plant samples. The machine used was EXD-720 and the atmosphere was air. The analytical units are kilo electron volts and time is 100 seconds. Collimator is $10 \mathrm{~mm}$ and spin off.

\subsection{Qualitative Phytochemical Screening using Chemical Methods}

Qualitative tests for flavonoids, saponins, cardiac glycosides, terpenoids, anthraquinones, phenols, phylobatannins, and tannins were carried out in the plant extract using the methods given. The different phytochemicals present in the plant extract were determined by chemical methods. The phytochemicals present in the plant extracts of Cleome gynandra include saponins, flavonoids, tannins, alkaloids, cardiac glycosides, terpanoids and polyphenols. The freshly prepared spider plant crude extract was qualitatively analysed for the presence of the following phytochemicals

(i) Test for flavonoids (shinoda test)- according to Panchal and Parvez, 2019, $3 \mathrm{ml}$ of aqueous solution of the plant extract was heated with 3 pieces of magnesium turning and 3 drops of concentrated Hydrochloric acid are added and mixed. Observation of an orange pink colouration gives a positive test for flavonoids.

(ii) Test for polyphenols- according to Lovid et al, 2001, $3 \mathrm{ml}$ of $1 \% \mathrm{~K}_{3} \mathrm{Fe}(\mathrm{CN})_{6}$ and $1 \% \mathrm{FeCl}_{3}$ were mixed with to $2 \mathrm{ml}$ of the aqueous solution of plant extract. Observation of green or blue colouration indicated the presence of polyphenols.

(iii) Test for saponins the froth test was used $-0.2 \mathrm{ml}$ of the plant extract was put in different test tubes and $5 \mathrm{ml}$ of distilled water added and heated to boiling. Appearance of creamy mass of small bubbles (frothing) indicated the presence of saponins.

(iv) Test for tannins- $3 \mathrm{~g}$ of the plant extract was put in a test tube and water was added. The mixture was mixed and heated in a water bath. The mixture then underwent filtration and a few drops of $10 \%$ ferric chloride was added. The presence of tannins is shown by a dark green colouration.

(v) Test for cardiac glycosides (Keller-kilani test) - according to Panchal and Parvez, 2019, to a 5ml sample of the methanolic plant extract of the plant, $2 \mathrm{ml}$ of glacial acetic acid was added followed by adding $1 \mathrm{ml}$ of $2 \%$ ferric chloride solution and $1 \mathrm{ml}$ of concentrated sulfuric acid a greenish/violet or brown coloured ring formed at the interface shows that cardiac glycosides are present

(vi) Test for alkaloids- Five milliliters of $10 \%$ hydrochloric acid was mixed with $1 / 2$ an $\mathrm{ml}$ of the plant extract in a test tube. The mixture was heated for a period of 20 minutes. The mixture was then filtered 
after cooling. To a milliliter of the filtrate add $5 \mathrm{ml}$ of Myers and Draggerndorffs reagent was added. Formation of cream and orange coloured precipitate respectively indicated that alkaloids are present.

(vii) Test for terpernoids (Ketonic)- $1 \mathrm{ml}$ of 2, 4-dinitrophenylhydrazine solution was mixed with $2 \mathrm{ml}$ aqueous solution of plant extract. The presence of a yellow-orange colouration shows ketonic terpernoids are present.

(viii) Test for anthraquinones (Borntrager's reaction for free anthraquinones). One gram $(1 \mathrm{~g})$ of the powdered seed was placed in a dry test tube and $20 \mathrm{~mL}$ of chloroform was added. This was heated in steam bath for $5 \mathrm{~min}$. The extract was filtered while hot and allowed to cool. To the filtrate was added with an equal volume of $10 \%$ ammonia solution. This was shaken and the upper aqueous layer was observed for bright pink colouration as indicative of the presence of Anthraquinones. Control test were done by adding $10 \mathrm{~mL}$ of $10 \%$ ammonia solution in $5 \mathrm{ml}$ chloroform in a test tube.

\subsection{Qualitative Determination of Phytochemicals by Gas Chromatography Mass Spectrometry (GCMS) system}

Qualitative analysis and identification of phytochemicals of methanolic extract of Cleome gynandra was done by Gas Chromatography Mass Spectrometry (GCMS) analysis. The freeze-dried sample of the aqueous extract of Cleome gynandra was used for analysis of the phytochemical compounds by Gas Chromatography Mass Spectroscopy system. The AVG analytical 12-250 GCMS equipped with a Hawlet Packard 5890A was the equipment used. Mass spectrometer instrument was interfaced to Gas chromatography and was used employing the following conditions: column $1 \mathrm{HP}-5 \mathrm{~ms} \mathrm{5 \%}$ phenyl methyl silox: $325^{\circ} \mathrm{C} 30 \mathrm{~m}$ x $250 \mu \mathrm{m}$ x $0.25 \mu \mathrm{m}$. operating in electron impact mode at $2141.18 \mathrm{ev}$. ICIPE MSD (mass selective detector) chemstation was used with low mass of 38 and high mass of 550 . Ms zone was $230^{\circ} \mathrm{C}$ and a maximum of $250^{\circ} \mathrm{C}$ and the Ms Quad $150^{\circ} \mathrm{C}$ and a maximum of $200^{\circ} \mathrm{C}$. Sample inlet was GC and injection source is GC ALS. The injection volume was $1 \mu \mathrm{m}$ and carrier gas used was helium (99.999\%) was used as carrier gas at a constant flow of $1 \mathrm{ml} / \mathrm{min}$. The injector was set at split less mode with heater to $270^{\circ} \mathrm{C}$, pressure 8.8271 psi, total flow $11.2 \mathrm{ml} / \mathrm{mm}$ and septum purge $3 \mathrm{ml} / \mathrm{min}$. Oven programme was $35^{\circ} \mathrm{C}$ for 5 minutes, $10^{\circ} \mathrm{C} / \mathrm{min}$ to $280^{\circ} \mathrm{C}$ for 10.5 minutes and then $50^{\circ} \mathrm{C} / \mathrm{min}$ to $285^{\circ} \mathrm{C}$ for 29.9 minutes total run time was 70 minutes. The plant sample extract was dissolved in methanol and then filtered with a polymeric solid phase extraction (SPE) column and analysed in GCMS for the different available phytochemical compounds. Each compound is detected by the mass spectrometer and identified by the GCMS library

\subsection{Identification of Phytochemical Components of the Plants}

This was done by chemical method and by Gas Chromatography mass spectrometry (GCMS) methods. Interpretation of The GCMS mass spectrum interpretation was conducted using the database of National institute standard and technology (NIST) with greater than 62000 patterns.

\subsection{Data Analysis}

Data were means of 3 replications \pm standard deviation (SD). Statistical analysis was done using SPSS version 19. The data was subjected to one-way ANOVA which was adopted for comparison and the results were subjected to post hoc tests which include scheffe test and Turkey B test. The data were expressed as mean \pm standard error. P value $<0.05$ was considered significant. The research design was an experimental research design and the type of experimental design used was the Solomon four group designs.

\section{Results}

\subsection{Trace Metal Content for Cleome Gynandra as Determined by Total Reflection X-Ray Fluorescence (TXRF) System}

The table below shows the mineral content for the two plants based on analysis by Total Reflection X-Ray Fluorescence (TXRF) System. The two plants were found to contain trace metals that are important for health. This include selenium, iron, copper, zinc, manganese and cobalt, some heavy metals were also 
Charles et al., Adv. J. Grad. Res.; Vol. 8, Issue 1, pp: 18-26, July 2020

present which include arsenic, mercury, lead and nickel. The concentrations are shown in the table below (Table 1)

Table 1: Trace metal content for Cleome gynandra as determined by Total Reflection X-ray Fluorescence System (TXRF System)

\begin{tabular}{|l|c|}
\hline Mineral & $\begin{array}{c}\text { Concentration in parts per million }(\mathbf{m g} / \mathbf{k g}) \pm \mathbf{S E} \\
\text { for Cleome gynandra }\end{array}$ \\
\hline Selenium & $1.000 \pm 0.66$ \\
\hline Iron & $3.803 \pm 1.12$ \\
\hline Manganese & $13.242 \pm 2.04$ \\
\hline Cobalt & $33.870 \pm 1.17$ \\
\hline Molybdenum & $101.523 \pm 0.59$ \\
\hline Zinc & $1.244 \pm 0.62$ \\
\hline Vanadium & $0.000 \pm 0.00$ \\
\hline Copper & $1.000 \pm 1.21$ \\
\hline Mercury & $1.329 \pm 0.96$ \\
\hline Arsenic & $18.569 \pm 2.82$ \\
\hline Nickel & $26.502 \pm 0.87$ \\
\hline Lead & $1.000 \pm 1.59$ \\
\hline
\end{tabular}

\subsection{Qualitative Determination of Phytochemical Components of Cleome Gynandra by Chemical Method}

From the chemical analysis it was observed that saponins, cardiac glycosides, Ketonic terpanoids and polyphenols were highly present in the plant extract, Tannins were moderately present and alkaloids and flavonoids were faintly present in the plant extract while Anthraquinones were found to be absent. This is shown in the table 2 below

Table 2: Qualitative analysis of phytochemical components of Cleome gynandra by chemical method

\begin{tabular}{|c|c|}
\hline Test & Cleome gynandra \\
\hline Saponins & +++ \\
\hline Tannins & ++ \\
\hline Flavanoids & + \\
\hline Terpanoids (ketonic) & +++ \\
\hline Anthraquinones & - \\
\hline Alkaloids & + \\
\hline Cardiac glycosides & +++ \\
\hline polyphenols & +++ \\
\hline
\end{tabular}

\subsection{Qualitative Determination of Phytochemicals of Cleome Gynandra by Gas Chromatography Mass Spectrometry (GCMS) Analysis}

Below is the spectrum of Cleome gynandra after a 70 minute run of methanolic plant extract using GCMS. Each peak indicates a separate compound as separated by gas chromatography at a specific run time. The abundance of the chemicals is shown by the $\mathrm{y}$-axis and the runtime by the $\mathrm{X}$-axis. The most volatile 
Mineral and Phytochemical Composition of Cleome Gynandra Methanolic Extract

compounds are separated first and the least volatile compounds last. The GCMS spectrum is shown in figure 1

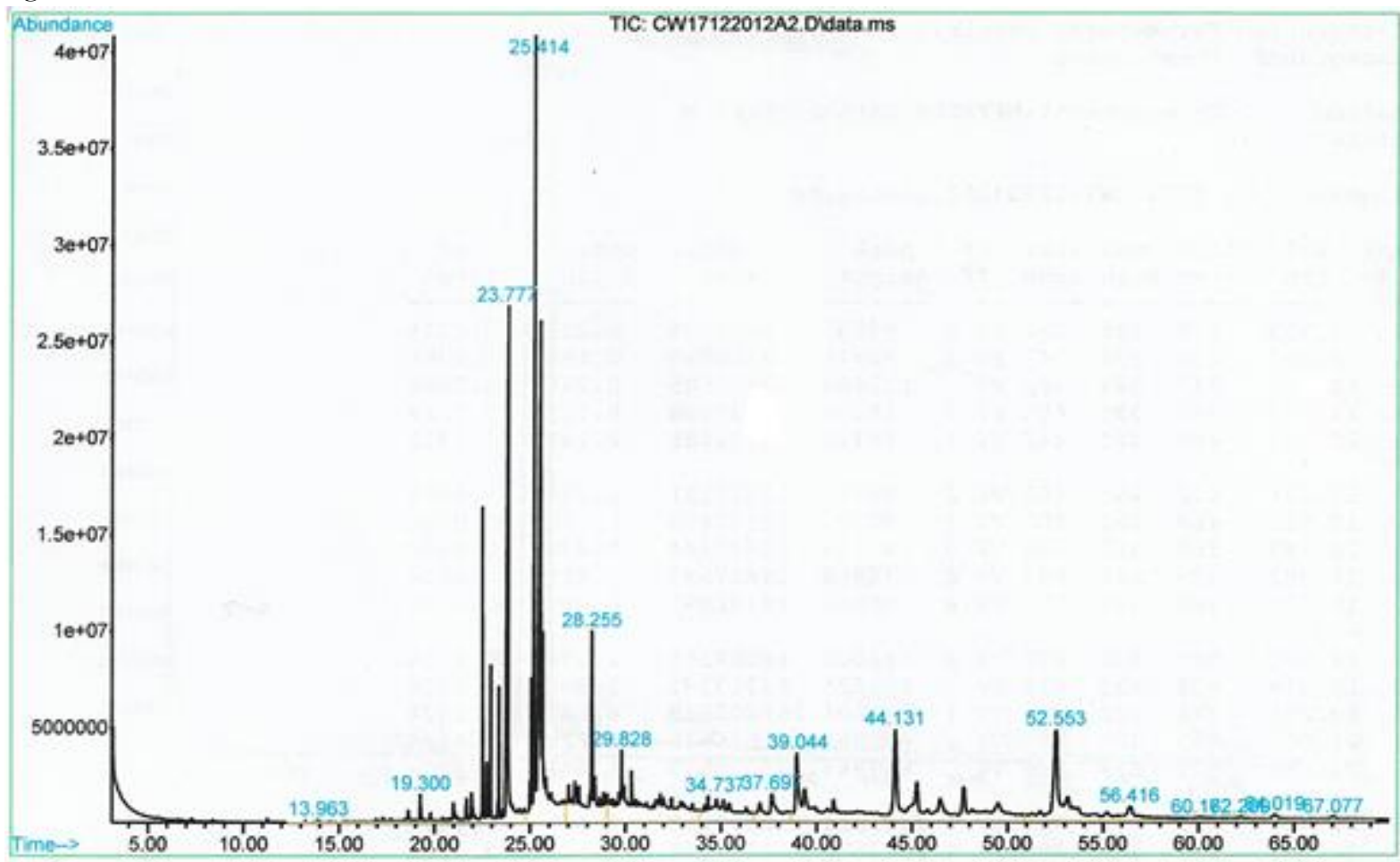

Figure 1: Gas Chromatography Mass Spectrometry (GCMS) spectrum of the Methanolic Extract of Cleome gynandra

\section{Discussion}

\subsection{Trace Metal Composition of Cleome Gynandra}

Results for the trace metal content analysis by Total Reflection X-Ray Fluorescence (TXRF) System clearly indicated that Cleome gynandra contain important trace metals with both antioxidant and nutritive importance in animals. The trace metals found in the extract of Cleome gynandra that have an important nutritional role in the cell are selenium which protects cells against oxidative stress, maintains defense against infection and modulates growth and development of cells and organisms [9,10]. In association with tocopherol, selenium is mainly involved in protection of cell membrane against oxidative damage. Selenium acts as a cofactor or activator for the enzyme glutathione peroxidase which is important antioxidant in cells and plays a role in neutralization of hydrogen peroxide $\left(\mathrm{H}_{2} \mathrm{O}_{2}\right)$ produced in cells during chemical reactions. The enzyme glutathione reductase involved in important antioxidant reactions in the cell required glutathione as a cofactor. Selenium is usually incorporated into selenoproteins like superoxide dismutase and also in thierodoxin reductase enzyme. Superoxide dismutase catalyzes the breakdown of hydrogen peroxide or lipid hydro peroxide and is a key enzyme in the bodies antioxidant system. The selenium requiring enzyme concentrations and their activity fall rapidly in the liver and blood at the early stages of selenium deficiency. The preclinical early stages of the progression of HIV infection is followed by a marked reduction of selenium in plasma and subclinical reduction in selenium, assumes increased importance in development of AIDS [11, 12]. The other RNA viruses virulence such as hepatitis B and others involved with occurrence of hemolytic anaemia are enhanced similarly by a selenium reduction. Iron which is another important trace metal present in Cleome gynandra. Iron is important in the formation of heme found in haemoglobin therefore important in the prevention of iron deficient anaemia [13]. Copper is another trace metal found in Cleome gynandra. Copper is present in more than a dozen enzymes as a cofactor in which some play an important role in the utilization of iron for the formation of haemoglobin and in skin pigmentation, examples of copper containing enzymes are ceruloplasmin, cytochrome oxidase, lysine oxidase and tyrosinase. Cobalt 
was also present in Cleome gynandra. Cobalt is important in vitamin $\mathrm{B}_{12}$ synthesis especially in bacteria (can be used by intestinal normal flora), some of the cobalt detected is in form of vitamin $\mathrm{B}_{12}$ (cobalamin). Vitamin $\mathrm{B}_{12}$ interacts with folic acid and mainly involved with transfer on one carbon groups in the cell, an example is in thymine synthesis which is a nitrogenous base (purine) used to form deoxyribonucleic acid (DNA). Folic acid and vitamin $\mathrm{B}_{12}$ are important in rapidly dividing cells like erythroid cells in the bone marrow during synthesis of erythrocytes and in early fetal development $[13,14]$. Zinc was also another trace metal detected in Cleome gynandra. Zinc activates the enzyme carbonic anhydrase found in the erythrocytes and is important for transport of carbon dioxide by erythrocytes to the lungs where carbon dioxide is excreted. Zinc is also important in normal reproduction in animals. Manganese is a trace metal important for proper bone development and is a cofactor in hexokinase enzyme responsible for energy synthesis in cells through the process of glycolysis therefore is important in energy production in the cell. Magnesium also activates bone enzyme alkaline phosphatase enzymes therefore it is required for normal bone development in animals [16].

\subsection{Phytochemical Composition of Cleome Gynandra}

The phytonutrient compounds present in the plant extract of Cleome gynandra have been shown to be responsible for the plant's pharmacological properties. These plants phytochemicals with pharmacological properties are mainly secondary metabolites of the plant's cellular metabolism. Cleome gynandra was found to contain a number of phytochemical secondary metabolites through qualitative chemical analysis and they include saponnins, flavonoids, tannins, alkaloids, cardiac glycosides, terpanoids and polyphenols [17]. The plant also had several sulfur or thiol compounds that could probably have the effect of scavenging of free radicals in cells by regenerating reduced glutathione or by direct interaction with the free radicals, therefore have antioxidant function, this were discovered by GCMS activity this include the thiol compound 2-nhexylthiol-5-methyl-imidazole. The spider plant also contained flavonoids. Flavonoids have also been reported to have strong antioxidant effect and could also have anti-inflammatory, anti-hepatotoxic (hepatoprotective), anticancer, antimicrobial and antiviral properties [18]. Flavonoids like Quercitrin which have strong antioxidant properties have been identified in previous studies involving Cleome gynandra [2,11]. Saponnins were highly present in Cleome gynandra according to chemical analysis. When sapponins are injected directly into the blood of animals they cause extravascular haemolysis of erythrocytes due to their saponification effect on cell membranes. Spider plant also contains alkaloids which have been found to act as stimulants while some have sedative effect $[17,19]$. Some bioactive compounds detected by Gas Chromatography Mass Spectroscopy (GSMS) method include benzoic acid derivatives have been found to have antimicrobial activity while phenol derivatives have Anti-microbial, Analgesic Anti-oxidant, Antiinflammatory properties. Phthalic acid has been found to have antifungal activity while vitamin $\mathrm{E}$ is an important fat-soluble antioxidant, the compound 7-dehydrodiosgenin and other plant sterols like stigmasterol, campesterol present in Cleome gynandra can be used as important starting materials for synthetic synthesis of steroid. Phytic acid has been reported to have antimictrobial and antiasthmatic effect while hexadecanoic acid methyl ester has been shown to have antimicrobial and antiallergic activity [19]. Cardiac glycosides which were also highly present in the spider plant have an effect on the heart by increasing muscle contraction. Cardiac glycosides like digoxin isolated from digitalis plant are also used in treatment of heart disease [20].

\section{Conclusions}

The studied plant Cleome gynandra contain important trace metals that are important for health in animals including humans which are important cofactors for a number of enzymes in the cell, like iron is important for synthesis of haemoglobin and red blood cells and some which reduce oxidative stress in the cell that is selenium, copper, iron, manganese, cobalt and zinc therefore have antioxidant properties. The spider plant also contains some heavy metals like nickel, mercury, silver and lead which may be responsible in causing toxicity in the body. The studied plant Cleome gynandra also contains important phytochemicals which may 
have important medicinal value like saponins, flavonoids, tannins, alkaloids, cardiac glycosides, terpanoids and polyphenols as well as some thiol compounds which have important pharmacological properties in animals. The plant (Cleome gynandra) can also be used as an important nutritional source of some essential nutrients like Vitamin $\mathrm{C}$, vitamin $\mathrm{E}$ and beta carotene which are vitamin antioxidants and play a role in prevention of cancer and haemolytic anaemia in humans. The spider plant can also be used as a good source of some trace mineral elements like iron, selenium, cobalt, copper, zinc and manganese. The spider plants pharmacological and nutritional properties can be important for families in rural areas and for the lowincome households in both rural and urban areas as a source of important nutrients since the plant is readily available and easy to cultivate. However more research needs to be done to determine the most important phytochemicals with medicinal value and their effectiveness as important therapeutic agents in treatment of specific diseases and the plant toxicity should also be determined. The plant can also be used as a cheap source of saponnins where the steroidal part of the molecule can be used in the synthesis of steroid hormones and other synthetic steroids with important physiological effect. Finally, more research needs to be done on toxicity and dosage of the different phytochemicals and heavy metals.

\section{Declarations}

\subsection{Acknowledgements}

We would like to thank the International Centre of Insect Physiology and Ecology (ICIPE) for their immense help in making GCMS analysis of the plant extract. I would like to also thank the staff at Kenyatta University and Mount Kenya University research laboratories for their guidance in this research.

\subsection{Competing Interests}

Author declared that no conflicts of interest exist in this publication.

\section{How to Cite this Article:}

C. Wakhisi, G. Michael, and E. Mwangi, "Mineral and Phytochemical Composition of Cleome Gynandra Methanolic Extract”, Adv. J. Grad. Res., vol. 8, no. 1, pp. 18-26, Apr. 2020. https://doi.org/10.21467/ajgr.8.1.18-26

\section{References}

[1] D. Sivakumar, L. Chen, Y. Sultanbawa. A comprehensive review on beneficial dietary phytochemicals in common traditional Southern African leafy vegetables. Food Science and Nutrition; 6:714-727, 2018.

[2] A. Partha and P. Satya. Medicinally important plant Cleome gynandra: a phytochemical and pharmacological explanation. Asian Journal of Pharmaceutical and Clinical Research. 2008.

[3] A. T. Mbaveng, V. Kuete and T. Efferth. Potential of Central, Eastern and Western Africa Medicinal Plants for Cancer Therapy: Spotlight on Resistant Cells and Molecular Targets. Frontiers of Pharmacology, Jun 2017.

[4] V. H. Erika \& V. Sonja. Nutritional and medicinal properties of Cleome gynandra. Acta Horticulturae. 752. 127-130.2007.

[5] M. Neffati, H. Najjaa and Á. Máthé. Medicinal and Aromatic Plants of the World - Africa Volume 3 - Jan 2017.

[6] K.M. Mugisha and H.O. Origa. (2007). Medicinal plants used to induce labour during childbirth in western Uganda. Journal of Ethnopharmacology. 109: 1-9.2007.

[7] J.M. Edmonds and J. A. Chweya. (1997). Black nightshades.Solanum nigrum L. and related species. Promoting the conservation and use of underutilized and neglected crops. Institute of Plant Genetic and Crop Plant Research, Gaterleben/International Plant Genetic Resources Institute, Rome, Italy. 112.

[8] H. Singh, A.Mishra and A. K. Mishra._The chemistry and pharmacology of Cleome genus: A review Author links open overlay panel. Biomedicine \& Pharmacotherapy: 101;37-48. May 2018.

[9] A. Gupta, P. Khenduja, R. M. Pandey, H. C. Sati, N. Y. Sofi, U. Kapil. Dietary Intake of Minerals, Vitamins, and Trace Elements Among Geriatric Population in India. Biology Trace Element Research.;180(1):28-38. Nov. 2017.

[10] M.A. Zoroddu; J. Aashet; G. Crisponi; S. Medici; M. Peana; V.M. Nurchi. "The essential metals for humans: a brief overview". Journal of Inorganic Biochemistry. 195: 120-129. Jun 2019.

[11] M. Moyo, S. O. Amoo, A. O. Aremu, J. Gruz, M. Šubrtová, M. Jarošová, P.Tarkowski, and K. Doležal. Determination of Mineral Constituents, Phytochemicals and Antioxidant Qualities of Cleome gynandra, Compared to Brassica oleracea and Beta vulgaris. Frontier Chemistry. 2017; 5: 128. Jan 2018.

[12] A.J. Lack and D.E. Evans. (2005). Plant Biology (instant notes). BIOS Scientific Publishers Ltd. Oxford. United Kingdom.

[13] T. B. Preeti , R. M. Satya and H. Mohsina. Nutritional Aspects of Essential Trace Elements in Oral Health and Disease: An Extensive Review. Scientifica (Cairo): 5464373. 2016.

[14] B. Muriel, H. Sabine, O. Marion, K. Esther, H. Jean-François and M. Irène. 2016. Dietary copper and human health: Current evidence and unresolved issues. Journal of Trace Elements in Medicine and Biology. 35: 107-115. 2016. 
Charles et al., Adv.J. Grad. Res.; Vol. 8, Issue 1, pp: 18-26, July 2020

[15] L. Imanirampa and P.E. Alele. Antifungal activity of Cleome gynandra L. aerial parts for topical treatment of Tinea capitis: an in vitro evaluation. BMC Complement Alternative Medicine 16, 194. 2016.

[16] L. B. Kathryn, A. C. Cathryn, K. Rozanne and C. Jane. Dietary Determinants of and Possible Solutions to Iron Deficiency for Young Women Living in Industrialized Countries: A Review. Nutrients. 6 (9): 3747-3776. 2014.

[17] N. Sridhar, B. V. Kiran, D. T. Sasidhar, L. K. Kanthal. In vitro antimicrobial screening of methanolic extracts of Cleome chelidonii and Cleome gynandra. Bangladesh Journal of Pharmacology. 30; 9(2):161-6. Mar 2014.

[18] A.J. Lack and D. E. Evans. Plant Biology (instant notes). BIOS Scientific Publishers Ltd. Oxford. United Kingdom. 2005.

[19] M.S. Rukshana, A. Doss. and T. P. Rani. Phytochemical Screening and GC-MS Analysis of Leaf Extract of Pergularia daemia (Forssk) Chiov. Asian Journal of Plant Science and Research, 7(1):9-15. 2017.

[20] N. Morsy. Cardiac Glycosides in Medicinal Plants. Intech. Chapter 2; Pages 29-45. 2017.

Publish your books with AIJR publisher-

- $\quad$ Publish with ISBN and DOI.

- Publish Thesis/Dissertation as Monograph.

- Publish Book Monograph.

- Publish Edited Volume/ Book.

- Publish Conference Proceedings

- Retain full copyright of your books.

Submit your manuscript at books.aijr.org
Publish your research article in AIJR journals-

- Online Submission and Tracking

- Peer-Reviewed

- Rapid decision

- Immediate Publication after acceptance

- Articles freely available online

- Retain full copyright of your article.

Submit your article at journals.aijr.in 